\title{
Diversidade genética de matrizes e progênies de Euterpe edulis Mart. em área manejada e em populações naturais por marcadores microssatélites
}

\author{
Genetic diversity in matrices and progenies of Euterpe edulis Mart. in managed \\ area and in natural populations by microsatellites markers
}

\section{Mariana Cardozo de Moraes ${ }^{\mathrm{I}}$; Liana Hilda Golin Mengarda ${ }^{\mathrm{II}}$; Guilherme Bravim Canal ${ }^{\mathrm{III}}$; Pedro Mazzoco Pereira ${ }^{\mathrm{IV}}$; Adésio Ferreirav $^{\mathrm{v}}$; Marcia Flores da Silva Ferreira ${ }^{\mathrm{v}}$}

\begin{abstract}
Resumo
Euterpe edulis, uma palmeira ameaçada de extinção da Mata Atlântica, tem importância ecológica e econômica pelo uso da polpa dos frutos. A identificação de matrizes geneticamente divergentes nas populações é útil para a conservação e o melhoramento da espécie. Neste trabalho, objetivou-se estimar a diversidade genética de plantas divergentes morfologicamente que possam ser utilizadas como matrizes, e de suas famílias de progênies em uma área manejada e em áreas de populações naturais da espécie no estado do Espírito Santo. Foram avaliadas 21 matrizes, das quais 13 obtidas em área manejada para a exploração sustentável dos frutos (anteriormente avaliadas quanto a caracteres de frutos) e oito oriundas de populações naturais no estado do Espírito Santo. Para cada matriz avaliou-se 10 progênies, constituindo 21 famílias. A partir de genotipagem por marcadores microssatélites, a caracterização das plantas matrizes e suas progênies foi realizada pelas heterozigosidades observada $\left(H_{o}\right)$ e esperada $\left(H_{e}\right)$ e o índice de endogamia (f), bem como a análise de variância molecular das plantas oriundas dos diferentes locais de coleta. As matrizes da área de cultivo manejada de Rio Novo do Sul apresentaram maiores $H_{o}$ e $H_{e}$, e menor $f$, indicando maior diversidade. Menores $H_{o}(0,36)$ e $H_{e}(0,41)$ e maior $f(0,15)$ foram observados para as matrizes de Pinheiros, indicando menor diversidade e maior endogamia. A análise da variância entre os locais de coleta das matrizes revelou maior variação genética intrapopulacional que interpopulacional. As matrizes coletadas em populações naturais, Linhares e, especialmente, de Pinheiros, apresentam menor diversidade genética. Na área manejada, os indivíduos apresentaram maior diversidade para as matrizes e suas progênies, indicando potencial para a conservação e uso sustentável do recurso genético nesta área. As matrizes indicadas para cruzamento, com possibilidade de gerar descendentes com maior desempenho morfológico para frutos e alta diversidade foram RNS_154 e RNS_76.
\end{abstract}

Palavras-chave: Palmeira juçara; SSR; Genética de populações; Manejo sustentável

Engenheira Florestal, Universidade Federal do Espírito Santo, Alto Universitário, s/n, CEP 29500-000, Alegre (ES), Brasil. maricardozo996@gmail. com (ORCID: 0000-0001-6267-9029)

Bióloga, Pós-doutora, Programa de Pós-graduação em Genética e Melhoramento, Universidade Federal do Espírito Santo, Alto Universitário, s/n, CEP 29500-000, Alegre (ES), Brasil. limengarda@gmail.com (ORCID: 0000-0002-8462-3701)

III Engenheiro Florestal, MSc., Programa de Pós-graduação em Produção Vegetal, Universidade Federal do Espírito Santo, Alto Universitário, s/n, CEP 29500-000, Alegre (ES), Brasil. guilhermecbravim@gmail.com (ORCID: 0000-0002-2691-1270)

IV Biólogo, Dr., Programa de Pós-graduação em Biologia Vegetal, Universidade Federal do Espírito Santo, Av. Fernando Ferrari, 514, Goiabeiras, CEP 29075-910, Vitória (ES), Brasil. pedromazoco@hotmail.com (ORCID: 0000-0002-6304-5156)

Agrônomo / Bióloga, Dr.(ra.), Professor(a) Associado(a) do Departamento de Agronomia, Universidade Federal do Espírito Santo, Alto Universitário, s/n, CEP 29500-000, Alegre (ES), Brasil. adesioferreira@gmail.com (ORCID: 0000-0002-7000-1725) / mfloressf@gmail.com (ORCID: 0000-0003-15416634) 


\begin{abstract}
Euterpe edulis, an endangered palm tree from the Atlantic Forest, has ecological and economic importance through the use of fruit pulp. Identifying genetically divergent matrices in populations is useful for species conservation and breeding. The present study aimed to estimate the genetic diversity of morphologically divergent plants that may be used as stock specimens as well as that of their progeny families, in a managed area and in areas of natural populations of the species in the state of Espírito Santo, Brazil. Twenty-one matrices were evaluated, of which 13 were obtained from areas managed for the sustainable exploitation of fruits (previously evaluated for fruit traits) and eight from natural populations in the state of Espírito Santo. For each matrix, 10 progenies were evaluated, constituting 21 families. From microsatellite marker genotyping, the characterization of the parent plants and their progenies was performed by the observed $\left(H_{\rho}\right)$ and expected $\left(H_{e}\right)$ heterozygosities and the inbreeding index $(\mathrm{f})$, as well as the molecular variance analysis of the plants from the different plants. The matrices of the managed area of Rio Novo do Sul presented higher $H_{o}$ and $H_{\rho}$, and lower $\mathrm{f}$, indicating greater diversity. Lower $H_{o}(0.36)$ and $H_{e}(0.41)$ and higher $f(0.15)$ were observed for Pinheiros matrices, indicating lower diversity and inbreeding. Analysis of variance between the collection sites of the matrices revealed greater intrapopulation than interpopulation genetic variation. The matrices collected from natural populations, Linhares and, especially, from Pinheiros, present less genetic diversity. In the managed area, the individuals presented greater diversity for the matrices and their progenies, indicating potential for the conservation and sustainable use of the genetic resource in this area. The matrices indicated for breeding, with the possibility of generating descendants with higher morphological performance for fruits and high diversity were RNS_154 and RNS_76.
\end{abstract}

Keywords: Juçara palm tree; SSR; Population genetics; Sustainable management

\title{
Introdução
}

Euterpe edulis (palmeira juçara) éuma espécie florestal de importância agroecológica. É considerada uma espécie-chave da Mata Atlântica por seus frutos amadurecerem em época de escassez de recursos na floresta, sendo fonte de alimento para um grande número de aves e mamíferos (GENINI; GALETTI; MORELLATO, 2009). Embora tenha importância ecológica as populações estão sendo reduzidas devido tanto à fragmentação das florestas, como também por sua regeneração natural ser limitada drasticamente pela intensa exploração do seu palmito (LIMA; FRANCO; SCHUMACHER, 2008) a qual resulta na supressão da planta, uma vez que a palmeira juçara tem um único estipe, não perfilha e não rebrota (GUIMARÃES; SOUZA, 2017).

A polpa produzida a partir dos seus frutos é muito similar à produzida pelo açaí, E. oleraceae, e o potencial de uso sustentável da palmeira juçara pela produção de frutos tem chamado atenção (COSTA et al., 2006; SCHULZ et al., 2016). O uso sustentável da espécie estimula o seu plantio em reflorestamentos e a implantação de cultivos agroecológicos, ações que contribuem para a manutenção da variabilidade genética da espécie, que se encontra ameaçada de extinção (BRASIL, 2008).

Euterpe edulis é uma espécie alógama, com protandria acentuada (MANTOVANI; MORELLATO, 2000) e taxas de fecundação cruzada próximas de 1,0 (REIS, 1996; GAIOTTO; GRATTAPAGLIA; VENCOVKSY, 2003; CONTE et al., 2008). Assim, em famílias naturais espera-se encontrar alta variabilidade, constituindo uma representação da diversidade genética existente nas populações nas quais as plantas matrizes estão inseridas. No entanto, a fragmentação florestal ocasiona a redução das populações naturais, da diversidade genética, podendo ocasionar o aumento da endogamia nas populações, limitando a variabilidade das progênies (GAIOTTO; GRATTAPAGLIA; VENCOVKSY, 2003; CONTE et al., 2008).

$\mathrm{O}$ conhecimento da variabilidade genética entre matrizes e entre e dentro de suas progênies permite identificar as matrizes representativas da variabilidade genética existente nas populações e também caracterizar a situação de conservação da área em estudo com base na variabilidade genética dos indivíduos do local (OLIVEIRA et al., 2004; OLIVEIRA; FERREIRA; SANTOS, 2007).

Dessa forma, com intuito de pré-melhoramento, é necessário caracterizar a diversidade genética de populações naturais em contraste com área de manejo de Euterpe edulis. Neste estudo objetivou-se estimar a diversidade genética de plantas divergentes morfologicamente que possam ser utilizadas como matrizes, e de suas famílias de progênies em uma área manejada e em áreas de populações naturais da espécie no estado do Espírito Santo. 


\section{Material e métodos}

\section{Material biológico e área de estudo}

As matrizes de Euterpe edulis amostradas para o estudo estão listadas na Tabela 1 (Figura 1). Das 21 matrizes, 13 foram de oriundas de área de cultivo manejada em propriedade rural particular no município de Rio Novo do Sul, Espírito Santo (ES) e oito foram oriundas de populações naturais de unidades de conservação da região Norte do ES. Das matrizes coletadas em populações naturais, cinco foram coletadas na Reserva Biológica do Córrego do Veado (CV), no município de Pinheiros; e três na Reserva Natural da Vale (V), no município de Linhares. Para a extração de DNA foram coletadas amostras de córtex das 21 plantas matrizes. As plantas foram amostradas aleatoriamente, considerando indivíduos adultos em estádio reprodutivo, as quais se apresentavam produzindo e com frutos maduros. Entre as matrizes amostradas na área manejada (Rio Novo do Sul), encontram-se algumas matrizes selecionadas num estudo prévio realizado com 138 indivíduos, quando foi aplicado o índice de seleção de Mulamba e Mock para identificar matrizes de alto desempenho morfológico com base nos caracteres dos frutos e sementes, visando estudos de pré-melhoramento (CANAL, 2016) (Tabela 1). De cada uma das 21 matrizes, foram obtidas 10 plântulas por meio da germinação de sementes coletadas, constituindo as famílias de meio irmãos de cada matriz. Para a extração do DNA foi coletada uma amostra de folha de cada uma das plântulas.

Tabela 1 - Identificação das 21 matrizes e suas respectivas famílias na área manejada no município de Rio Novo do Sul (RNS) e nas populações naturais nos municípios de Linhares (L) e Pinheiros (P), ES, Brasil. Valor médio de massa fresca dos frutos (MFF), em gramas (g), e classificação no ranqueamento (Ran) obtido pelo índice de seleção de Mulamba e Mock, segundo Canal (2016)

Table 1 - Identification of the 21 matrices and their respective families in the managed area in Rio Novo do Sul (RNS) city and natural populations in the municipalities of Linhares (L) and Pinheiros (P), ES, Brazil: mean value of fresh fruit mass (MFF), in grams (g), and classification in the rankings obtained by the Mulamba and Mock selection index, according to Canal (2016)

\begin{tabular}{lcclcc}
\hline \multicolumn{1}{c}{ Matriz } & Família & Indivíduos & Município & MFF(g) & Ran \\
\hline RNS_17 & 1 & $1-10$ & Rio Novo do Sul & 1,53 & - \\
RNS_131 & 2 & $11-20$ & Rio Novo do Sul & 1,50 & - \\
RNS_143 & 3 & $21-30$ & Rio Novo do Sul & 1,35 & - \\
RNS_154 & 4 & $31-40$ & Rio Novo do Sul & 1,96 & $\mathbf{6}^{-}$ \\
RNS_157 & 5 & $41-50$ & Rio Novo do Sul & 1,43 & - \\
RNS_67 & 13 & $51-60$ & Rio Novo do Sul & 1,40 & - \\
RNS_75 & 14 & $61-70$ & Rio Novo do Sul & 1,94 & $22^{\circ}$ \\
RNS_76 & 15 & $71-80$ & Rio Novo do Sul & 1,85 & $17^{\circ}$ \\
RNS_100 & 16 & $81-90$ & Rio Novo do Sul & 1,37 & - \\
RNS_114 & 17 & $91-100$ & Rio Novo do Sul & 1,05 & - \\
RNS_120 & 18 & $101-110$ & Rio Novo do Sul & 2,58 & $1^{\mathbf{0}}$ \\
RNS_141 & 19 & $111-120$ & Rio Novo do Sul & 1,22 & -
\end{tabular}


Tabela 1 - Conclusão ...

Table 1 - Conclusion ...

\begin{tabular}{lccccc}
\hline \multicolumn{1}{c}{ Matriz } & Família & Indivíduos & Município & MFF(g) & Ran \\
\hline RNS_183 & 20 & $121-130$ & Rio Novo do Sul & 1,10 & - \\
L_32 & 10 & $131-140$ & Linhares & 1,37 & - \\
L_33 & 11 & $141-150$ & Linhares & 0,78 & - \\
L_39 & 12 & $151-159$ & Linhares & 0,98 & - \\
P_1 & 6 & $161-170$ & Pinheiros & 0,72 & - \\
P_2 & 7 & $171-180$ & Pinheiros & 0,82 & - \\
P_3 & 8 & $181-190$ & Pinheiros & 0,86 & - \\
P_10 & 9 & $191-200$ & Pinheiros & 1,09 & - \\
P_21 & 21 & $201-208$ & Pinheiros & 1,06 & - \\
\hline
\end{tabular}

Fonte: Canal (2016)

Figura 1 - Localização geográfica das 21 matrizes de Euterpe edulis, na área de manejo do município de Rio Novo do Sul, e das duas populações naturais nos municípios de Linhares e Pinheiros, ES, Brasil

Figure 1 - Geographic location of the 21 matrices of Euterpe edulis covering the managed area in the municipality of Rio Novo do Sul, and the two natural populations in the municipalities of Linhares and Pinheiros, ES state, Brazil

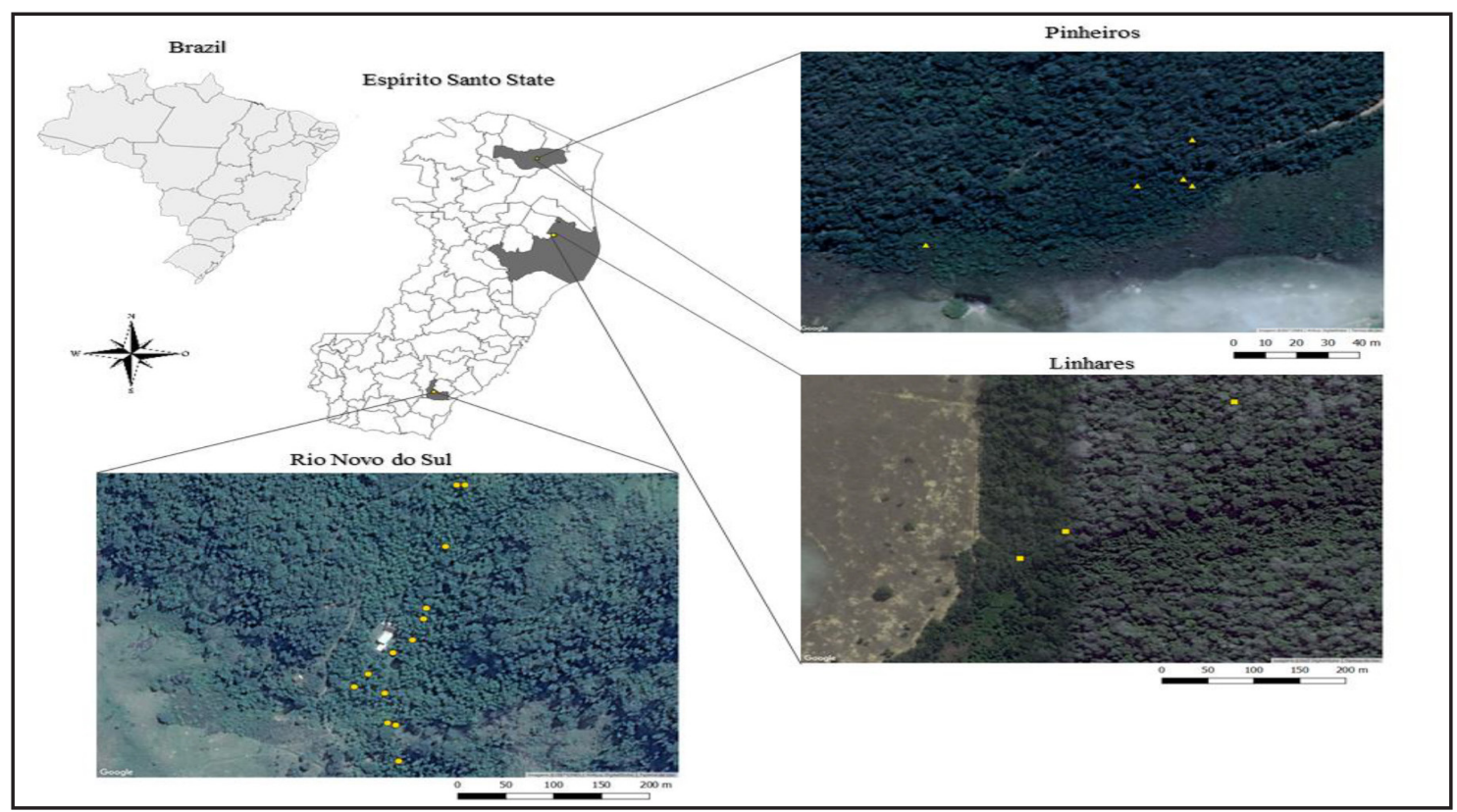

Fonte: Autores (2019) 


\section{Análises moleculares}

O DNA genômico das plantas matrizes foi isolado a partir de segmentos de córtex. Para as plântulas utilizou-se material foliar. A extração de DNA foi baseada no método CTAB (DOYLE; DOYLE, 1990) com modificações. Foram realizadas de duas a três replicatas de extração do DNA e a amostra de melhor qualidade foi utilizada para as amplificações. As concentrações de DNA das amostras foram estimadas por espectrofotometria e a integridade do DNA foi verificada em gel de agarose $0,8 \%$.

As amplificações dos microssatélites foram realizadas utilizando-se oito microssatélites desenvolvidos para a espécie (GAIOTTO; BRONDANI; GRATTAPAGLIA, 2001). A reação de PCR foi de um volume de $13 \mu \mathrm{L}$ composta por: 30 ng de DNA genômico; 1X de tampão I0 (Phoneutria); $0,15 \mu \mathrm{M}$ de cada primer (forward e reverse); $1,5 \mathrm{mM} \mathrm{MgCl}_{2} ; 0,25 \mathrm{mM} \mathrm{dNTPs}$; e 1 unidade de Taq DNA polimerase. O programa utilizado foi: $94^{\circ} \mathrm{C}$ por quatro minutos; 30 ciclos compostos por $94^{\circ} \mathrm{C}$ por um minuto e meio; temperatura de anelamento do primer (GAIOTTO; BRONDANI; GRATTAPAGLIA, 2001) por um minuto; $72^{\circ} \mathrm{C}$ por um minuto; uma extensão final de $72^{\circ} \mathrm{C}$ por 7 minutos. Os produtos de amplificação foram separados por eletroforese em géis de poliacrilamida $10 \%$ e tampão TBE $1 \mathrm{x}$ a 100 volts e corados com GelRed (1,33 x).

\section{Análises de dados}

As análises de diversidade foram feitas por matrizes e por famílias, considerando as três localidades de coleta (área manejada em Rio Novo do Sul, e populações naturais de Linhares e Pinheiros). Também foram determinados os índices de diversidade entre e dentro de cada uma das 21 famílias de meio irmãos.

Como análise descritiva da diversidade estimou-se: o número de alelos $(A)$, heterozigosidade esperada $(\mathrm{He})$, heterozigosidade observada $\left(H_{o}\right)$ e coeficiente de endogamia $(f)$, pelo programa GDA. A diferenciação intra e interpopulacional foi estimada por análise de variância molecular (AMOVA), com dois níveis hierárquicos, utilizando o programa Arlequin.

As relações genéticas entre os indivíduos (das matrizes e das famílias, separadamente) foram avaliadas por meio de matriz de dissimilaridade, construída com uso do complemento do índice de similaridade, pelo programa Genes (CRUZ, 2013), com a qual foi realizada a análise de Coordenadas Principais (PCoA) utilizando o programa DARWin 6.0.14. Também foi estimada a média das distâncias genéticas entre os indivíduos de cada uma das 21 famílias, sendo esses valores plotados em gráfico de barras com respectivo erro padrão da média.

\section{Resultados e discussão}

Considerando as análises das plantas e matrizes, a $H_{e}$ variou de 0,41 (Pinheiros) a 0,54 (Rio Novo do Sul), a Ho variou de 0,35 (Pinheiros) a 0,59 (Rio Novo do Sul). O menor coeficiente de endogamia ocorreu em Rio Novo do Sul $(f=-0,08)$, sendo maior para as matrizes de Pinheiros $(f=0,15)$ (Tabela 2$)$. 
Tabela 2 - Estimativas dos índices de diversidade genética para as matrizes coletadas nos três municípios e para as 208 progênies das 21 famílias de meios irmãos

Table 2 - Estimates of genetic diversity indexes for plant matrices and for the 208 progenies of the 21 half-sib families

\begin{tabular}{|c|c|c|c|c|c|c|c|}
\hline Local de coleta & Família & $\mathbf{N}$ & $\mathbf{A}$ & Ap & $\mathbf{H}_{\mathrm{e}}$ & Ho & $\mathbf{f}$ \\
\hline \multirow[t]{13}{*}{ Famílias de Rio Novo do Sul } & 1 & 7 & 2,13 & 2,29 & 0,38 & 0,62 & $-0,72$ \\
\hline & 2 & 8 & 1,88 & 2,75 & 0,31 & 0,47 & $-0,34$ \\
\hline & 3 & 8 & 1,75 & 2 & 0,33 & 0,54 & $-0,39$ \\
\hline & 4 & 8 & 1,63 & 2 & 0,25 & 0,36 & $-0,305$ \\
\hline & 5 & 9 & 1,88 & 2 & 0,36 & 0,56 & $-0,36$ \\
\hline & 13 & 8 & 2,13 & 2,29 & 0,41 & 0,42 & $-0,024$ \\
\hline & 14 & 8 & 1,75 & 2 & 0,28 & 0,36 & $-0,27$ \\
\hline & 15 & 8 & 1,88 & 2,17 & 0,32 & 0,37 & $-0,19$ \\
\hline & 16 & 8 & 1,75 & 2 & 0,24 & 0,36 & $-0,55$ \\
\hline & 17 & 9 & 2,13 & 2,13 & 0,4 & 0,56 & $-0,43$ \\
\hline & 18 & 8 & 1,75 & 2 & 0,24 & 0,29 & $-0,21$ \\
\hline & 19 & 8 & 2,13 & 2,13 & 0,45 & 0,7 & $-0,62$ \\
\hline & 20 & 9 & 1,75 & 2 & 0,17 & 0,17 & $-0,01$ \\
\hline Média das famílias de Rio Novo do Sul & & & 1,89 & 2,14 & 0,32 & 0,44 & $-0,42$ \\
\hline \multirow[t]{5}{*}{ Famílias de Pinheiros } & 6 & 9 & 1,63 & 2 & 0,21 & 0,33 & $-0,66$ \\
\hline & 7 & 8 & 1,63 & 2 & 0,25 & 0,38 & 0,56 \\
\hline & 8 & 9 & 1,75 & 2 & 0,23 & 0,29 & $-0,27$ \\
\hline & 9 & 9 & 1,75 & 2 & 0,23 & 0,33 & $-0,47$ \\
\hline & 21 & 9 & 1,75 & 3 & 0,19 & 0,28 & $-0,54$ \\
\hline Média das famílias de Pinheiros & & & 1,7 & 2,2 & 0,22 & 0,32 & $-0,5$ \\
\hline \multirow[t]{3}{*}{ Famílias de Linhares } & 10 & 8 & 1,75 & 2 & 0,3 & 0,43 & $-0,45$ \\
\hline & 11 & 8 & 1,88 & 2,17 & 0,35 & 0,49 & $-0,46$ \\
\hline & 12 & 8 & 1,88 & 2,17 & 0,31 & 0,37 & $-0,23$ \\
\hline Média das famílias de Linhares & & & 1,84 & 2,11 & 0,32 & 0,43 & $-0,38$ \\
\hline Média das famílias & & & 1.83 & 2,17 & 0,29 & 0,41 & $-0,44$ \\
\hline Matrizes de Rio Novo do Sul & & 13.00 & 3.00 & 3.00 & 0.54 & 0.59 & -0.08 \\
\hline Matrizes de Pinheiros & & 4.88 & 2.13 & 2.29 & 0.41 & 0.36 & 0.15 \\
\hline Matrizes de Linhares & & 2.88 & 2.00 & 2.14 & 0.48 & 0.50 & -0.06 \\
\hline Média das matrizes & & - & 2.38 & 2.48 & 0.48 & 0.48 & 0.01 \\
\hline
\end{tabular}

Fonte: Autores (2019)

Em que: N: tamanho da amostra; A: número médio de alelos por locus; Ap: proporção de loci polimórficos; $H_{E}$ : heterozigosidade média esperada; $H_{O}$ : heterozigosidade média observada; $f$ : coeficiente de endogamia ou índice de fixação de Wright (1978) 
As matrizes de Pinheiros apresentaram índice de endogamia positivo, indicando maior endogamia, bem como menor média de $H_{e}$, indicando menor diversidade. As matrizes de Rio Novo do Sul apresentaram maior média de $\mathrm{Ho}$ (Tabela 2), indicando maior diversidade genética. Entre as 208 progênies verificaram-se $H_{e}$ entre 0,26 a 0,62. Os valores médios de $H o$ em geral foram maiores que os de $H_{e}$. O coeficiente de endogamia (f) nas famílias variou de $-0,72$ a $-0,01$ (Tabela 2). O valor médio de coeficiente de endogamia para as famílias foi menor em relação às matrizes.

Assim como para as matrizes, as famílias de Rio Novo Sul tiveram as maiores médias de $\mathrm{He}(0,32)$ e de $\mathrm{Ho}(0,44)$, enquanto as famílias Pinheiros tiveram as menores médias dos índices de diversidade: $\mathrm{He}(0,22)$ e $\mathrm{Ho}(0,32)$.

Todas as famílias apresentaram baixos coeficientes de endogamia. Curiosamente, as famílias de Pinheiros, as quais apresentaram menor diversidade, apresentaram coeficientes de endogamia menores $(-0,50)$, o que indicaria indivíduos menos endogâmicos nas progênies. Tais resultados podem indicar o efeito de Wahlund, que afirma que um valor mais negativo de $f$ (o qual pode indicar que há mais indivíduos heterozigotos que o esperado) poderia acontecer nas primeiras gerações após duas populações anteriormente isoladas se tornarem uma (MARTINSCORDER et al., 2009) como, por exemplo, em casos de reflorestamento com estabelecimento de corredores ecológicos entre dois fragmentos florestais, voltando a haver fluxo gênico entre os indivíduos. Isso seria possível, também, considerando que a área de Pinheiros se trata de um espaço de preservação e o histórico sugere que tenham sido plantadas no local mudas de Euterpe edulis oriundas de matrizes de outras áreas, as quais podem ter fornecido material genético para os cruzamentos que geraram a progênie amostrada no presente estudo. Contrariando essa hipótese, os valores de heterozigosidade $(\mathrm{He}$ e $\mathrm{Ho}$ ) das matrizes amostradas não indicam para tal situação. Contudo, o efeito de Wahlund também explica que a seleção contra homozigotos durante o recrutamento e estabelecimento de mudas poderia afetar a resposta do coeficiente de endogamia (f). A seleção contra homozigotos nos estádios iniciais da vida poderia dar a impressão de heterozigosidade maior e, por consequência, coeficientes de endogamia menores (HUFFORD; HAMRICK, 2003), como o observado para as famílias de Pinheiros.

A análise da variância molecular (AMOVA) entre as populações de matrizes revelou 90\% da variabilidade genética dentro das populações (intrapopulacional) e 10\% entre as populações de matrizes (interpopulacional) (Tabela 3). Tal resultado corrobora as afirmações de autores como Kageyama et al. (2003) de que em plantas tropicais com taxas de fecundação cruzada próximas de 1,0 e com alta densidade populacional, assim como Euterpe edulis, a distribuição da variabilidade é maior dentro das populações que entre populações. Conte et al. (2008) também afirmam que as espécies tropicais como Euterpe edulis, com amplos intervalos geográficos, sistemas de cruzamentos transversais e altas taxas de fluxo de genes, têm maior variabilidade genética dentro das populações e, consequentemente, baixa divergência entre as populações.

A análise de variância entre as 21 famílias também revelou maior variabilidade genética intrapopulacional (57\%) que interpopulacional (43\%) (Tabela 3). Contudo, considerando as famílias, observou-se uma maior proporção da variação atribuída "entre", o que demonstra que as 21 famílias apresentam maior diferenciação entre si que as populações de matrizes. O valor de diferenciação genética entre as populações de matrizes $\left(\mathrm{F}_{\mathrm{ST}}\right)$ foi de 0,10 , e entre as famílias foi $0,43$, ambos significativos ( $\mathrm{p}<0,001)$. 
Tabela 3 - Análise de variância molecular entre e dentro das três populações de matrizes e entre e dentro das 21 famílias de Euterpe edulis

Table 3 - Molecular variance analysis between and within the three matrix populations and between and within the 21 Euterpe edulis families

\begin{tabular}{lcccc}
\hline & Fonte de variação & Soma de quadrados & Variância & Porcentagem \\
\hline \multirow{4}{*}{$\begin{array}{l}\text { Locais de amostras } \\
\text { das matrizes }\end{array}$} & Entre & 09,126 & 0,2241 & 10,001 \\
& Dentro & 77,516 & 2,0166 & 89,998 \\
& Total & 86,642 & 2,2407 & \\
\cline { 2 - 5 } & $\mathrm{F}_{\mathrm{ST}}$ & 00,100 & & \\
\hline \multirow{3}{*}{ Famílias } & Entre & 325,87 & 0,9087 & 43,295 \\
& Dentro & 389,94 & 1,1902 & 56,705 \\
& Total & 715,81 & 2,0989 & \\
\hline
\end{tabular}

Fonte: Autores (2019)

A análise de coordenadas principais (PCoA), obtida com base nas distâncias genéticas entre as 21 matrizes (Figura 2) indicou que as matrizes coletadas nas três localidades apresentam indivíduos geneticamente distantes entre si, e menos diversos dentro de cada população. Foi possível identificar as matrizes mais divergentes, a exemplo da matriz 12 (L_39) de Linhares e da matriz 4 (RNS_154) de Rio Novo do Sul (Figura 2 A). As matrizes 13, 14 e 18 foram menos divergentes.

Na PCoA entre as 208 progênies observaram-se distâncias maiores do que as distâncias observadas entre as matrizes (Figura 2B), confirmando o resultado observado na AMOVA. Os indivíduos das famílias de Rio Novo do Sul apresentaram-se mais distantes geneticamente dos indivíduos de Linhares e Pinheiros, que apresentaram maior proximidade (Figura 2 B). 
Figura 2 - Análise de coordenadas principais com base nas distâncias genéticas entre as 21 matrizes e entre as 208 progênies. Porcentagem da variação representada pelos dois eixos: A - entre as matrizes: eixo $1=27,05$; eixo $2=17,47$, soma $=44,97 \%$; $B$ - entre as progênies: eixo $1=12,81$, eixo $2=9,05$, soma $=21,86 \%$. Matrizes e progênies de Rio Novo do Sul são representadas na cor verde. Matrizes e progênies de Linhares são representadas na cor vermelha. Matrizes e progênies de Pinheiros são representadas na cor azul

Figure 2 - Principal coordinate analysis based on the genetic distances between the 21 matrices and among the 208 progenies. Percentage of the variation represented by the two axes: A between the matrices: axis $1=27.05$; axis $2=17.47$, sum $=44.97 \%$; $\mathrm{B}$ - among the progenies: axis $1=12.81$, axis $2=9.05$, sum $=21.86 \%$. Matrices and progenies of Rio Novo do Sul are represented in green. Matrices and progenies of Linhares are represented in red color. Matrices and progenies of Pinheiros are represented in blue

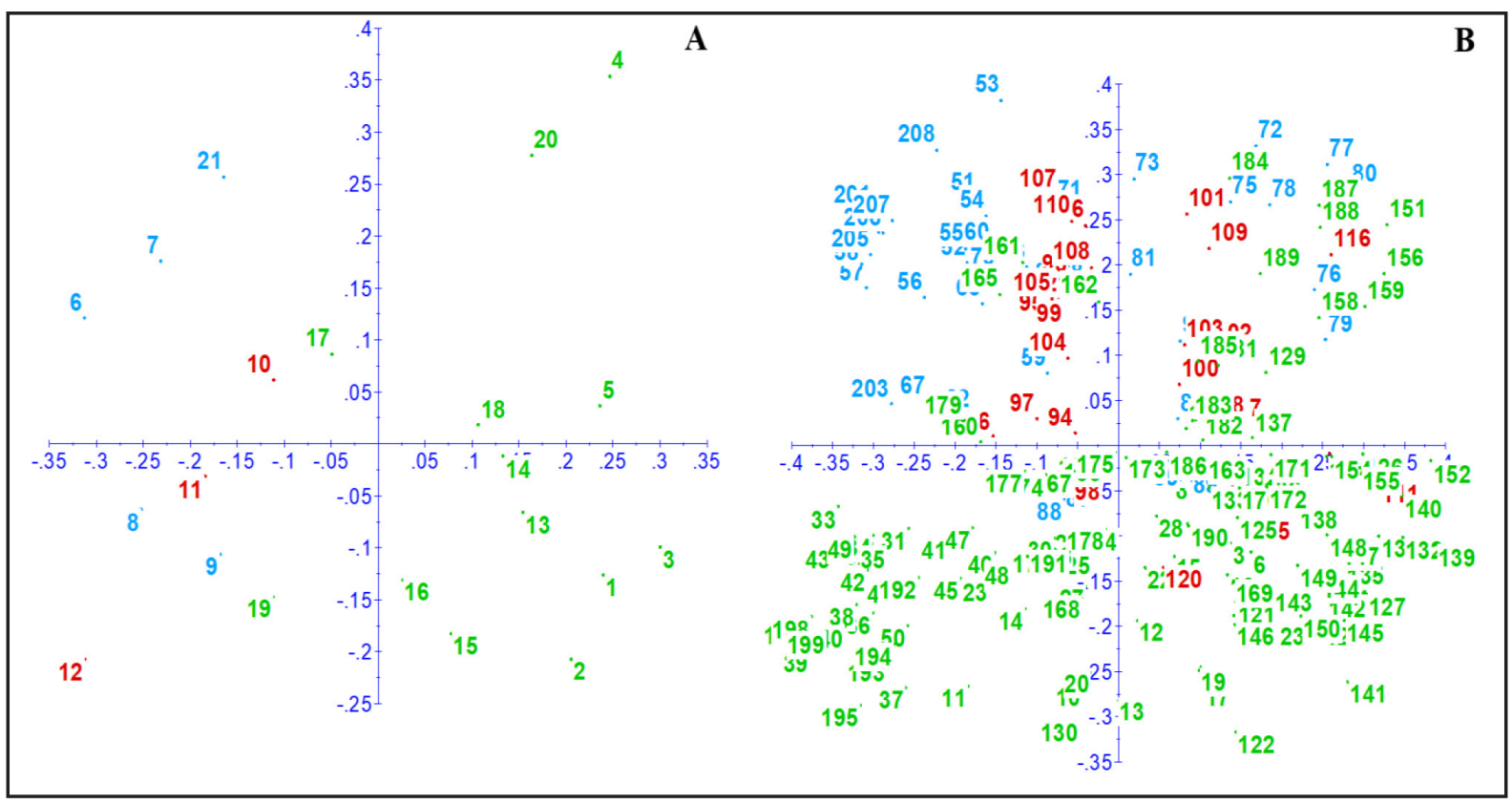

Fonte: Autores (2019)

A família oito (oriunda da matriz de Pinheiros) apresentou menor média de dissimilaridade genética entre as progênies (Figura 3), possuindo indivíduos mais similares. Em contraste, a família 13 (oriunda da matriz de Rio Novo do Sul) apresentou maior dissimilaridade de indivíduos na família. De modo geral, as famílias oriundas de matrizes da área de manejo apresentaram dissimilaridade genética de média $(\geq 0,25)$ à alta $(\geq 0,50)$, sendo menor que 0,25 apenas para as famílias 4 e 5 . As três famílias de Linhares apresentam dissimilaridade genética média; as cinco famílias de Pinheiros apresentam dissimilaridade de média $(\geq 0,25)$ à baixa $(\leq 0,25)$. Esses dados corroboram as análises de diversidade (Tabela 2), nas quais as maiores heterozigosidade $\left(H_{o}\right.$ e $\left.H_{e}\right)$ foram detectadas em Rio Novo do Sul, e menor diversidade, tanto para as matrizes quanto para as famílias, foi observada na população natural de Pinheiros. 
Figura 3 - Dissimilaridade genética média entre os indivíduos das 21 famílias de Euterpe edulis. As barras representam o erro padrão da média

Figure 3 - Mean genetic dissimilarity among individuals from the 21 families of Euterpe edulis.

The bars represent the standard error of the mean

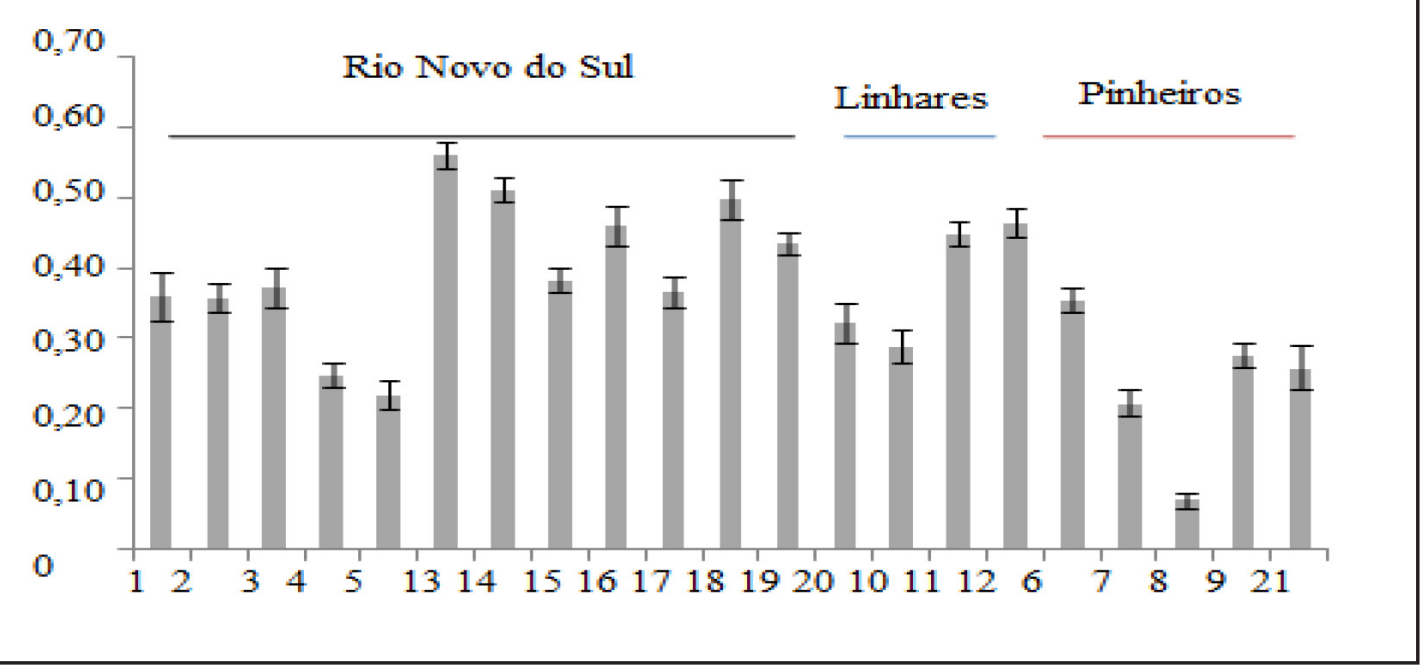

Fonte: Autores (2019)

Os resultados mostram que as matrizes coletadas em populações naturais de Euterpe edulis localizadas em Linhares e, especialmente, em Pinheiros, apresentam menor diversidade genética. A reprodução entre indivíduos de baixa variabilidade genética pode acarretar depressão endogâmica. Assim, sugere-se a implementação de estratégias in situ, introduzindo indivíduos alóctones para aumentar o tamanho efetivo da população além da inclusão de corredores ecológicos efetivos a fim de minimizar os efeitos adversos e promover a conservação da espécie.

$\mathrm{Na} \mathrm{PCoA}$ as matrizes que obtiveram uma maior distância com as matrizes de Linhares foram as 2 (RNS_131), 3 (RNS_143), 4 (RNS_154), e 21(P_21), sendo as matrizes indicadas para fornecer sementes e mudas para serem introduzidas em Linhares. Em Pinheiros, sugere-se introduzir mudas das matrizes 2 (RNS_131), 3 (RNS_143), 4 (RNS_154) e 12 (L_39).

Os indivíduos da área manejada de Rio Novo do Sul, embora estejam localizados em uma área de regeneração secundária e sob manejo, apresentam maiores índices de diversidade, indicando boa condição de conservação. As matrizes 18 (RNS_120) e 4 (RNS_154) estão entre as mais bem ranqueadas nos índices de seleção de Mulamba e Mock (Canal, 2016). Estas, assim como a matriz 15 (RNS_76), apresentam-se distantes entre si e das demais matrizes estudas pelo PCoA e poderiam ser indicadas como progenitoras para fornecer sementes e mudas, bem como para cruzamentos visando o melhoramento genético. 


\section{Conclusão}

As matrizes da área de cultivo manejada de Rio Novo do Sul- ES apresentaram maior diversidade genética em relação às matrizes coletadas em populações naturais em Linhares-ES e em Pinheiros-ES. Os indivíduos da área manejada apresentam grande potencial para a conservação e para uso sustentável. Foram identificadas entre plantas divergentes morfologicamente de Euterpe edulis de uma área de cultivo manejado, aquelas que podem ser utilizadas como matrizes, contribuindo para a conservação e o pré-melhoramento da espécie. As matrizes indicadas para cruzamentos com possibilidade de gerar descendentes com maior desempenho morfológico para frutos e alta diversidade genética são RNS_154, RNS_120 e RNS_76.

\section{Agradecimentos}

À FAPES, CAPES e CNPq, pela concessão de bolsas e financiamento de projeto. Aos senhores Pedro e Vicente Bortoloti, proprietários da área manejada de Rio Novo do Sul, ES.

\section{Refêrencias}

BRASIL. Ministério do Meio Ambiente. Instrução Normativa No 06, de 23 de setembro de 2008. Lista Nacional das Espécies da Flora Brasileira Ameaçada de Extinção. Diário Oficial da União, Brasília, DF, v. 185, p. 75-83, 2008.

CANAL, G. B. Seleção de matrizes de Euterpe edulis Martius por caracteres de frutos, sementes e muda. 2016. Trabalho de Conclusão de Curso (Bacharelado) - Universidade Federal do Espírito Santo, Espírito Santo, 2016.

CONTE, R. et al. Genetic structure and mating system of Euterpe edulis Mart. populations: a comparative analysis using microsatellite and allozyme markers. Journal of Heredity, Cary, v. 5, p. 476-482, 2008.

COSTA, E. A. et al. Produção de polpa e sementes dos frutos de Euterpe edulis Mart. - uma alternativa de geração de renda e uso sustentável da mata atlântica. Biológico, São Paulo, v. 68, p. 663-666, 2006.

CRUZ, C. D. GENES - a software package for analysis in experimental statistics and quantitative genetics. Acta Scientiarum, Maringá, v. 35, n. 3, p. 271-276, 2013.

DOYLE, J. J.; DOYLE, J. L. Isolation of plant DNA from fresh tissue. Focus, [s. 1.], v. 12, p. 13-15, 1990.

GAIOTTO, F. A.; BRONDANI, R. P. V.; GRATTAPAGLIA, D. Microsatellite markers for heart of palm - Euterpe edulis and E. oleracea Mart. (Arecaceae). Molecular Ecology, Oxford, v. 1, n. 1, p. 86-88, 2001.

GAIOTTO, F. A.; GRATTAPAGLIA, D.; VENCOVKSY, R. Genetic structure, mating system, and long-distance gene flow in heart of palm (Euterpe edulis Mart.). Journal of Heredity, Cary, v. 94, p. 399-406, 2003. 
GENINI, J.; GALETTI, M.; MORELLATO, L. P. C. Fruiting phenology of palms and trees in an Atlantic rainforest land-bridge island. Flora, Holzwiesenstr, v. 204, n. 2, p. 131-145, 2009.

GUIMARÃES, L. A. O. P.; SOUZA, R. G. Palmeira juçara: patrimônio natural da Mata Atlântica no Espírito Santo. Vitória: Incaper, 2017. 68 p.

HUFFORD, K. M.; HAMRICK, J. L. Viability selection at three early life stages of the tropical tree, Platypodium elegans (Fabaceae, Papilionoideae). Evolution, [s. l.], v. 57, p. 518-526, 2003.

KAGEYAMA, P. Y. et al. Diversidade genética em espécies arbóreas tropicais de diferentes estágios sucessionais por marcadores genéticos. Scientia Forestalis, Piracicaba, n. 64, p. 93-107, 2003.

LIMA, L. S. H.; FRANCO, E. T. H.; SCHUMACHER, M. V. Crescimento de mudas de Euterpe edulis Martius em resposta a diferentes doses de fósforo. Ciência Florestal, Santa Maria, v. 18, n. 4, p. 461-470, 2008.

MANTOVANI, A.; MORELlATO, P. Fenologia da floração, frutificação, mudança foliar e aspectos da biologia floral. Sellowia, Itajaí, v. 49/52, p. 23-38, 2000.

MARTINS-CORDER, M. P. et al. Diversidade genética em populações de Euterpe edulis Martius do Rio Grande do Sul, através de marcadores isoenzimáticos. Revista Ceres, Viçosa, MG, v. 56, p. 204-213, 2009.

OLIVEIRA, M. S. P.; FERREIRA, D. F.; SANTOS, J. B. Pesquisa Divergência genética entre acessos de açaizeiro fundamentada em descritores morfoagronômicos. Agropecuária Brasileira, Brasília, DF, v. 42, n. 4, p. 501-506, 2007.

OLIVEIRA, V. R. et al. Variabilidade genética de procedências e progênies de umbuzeiro via metodologia de modelos lineares mistos. Revista Brasil, Jaboticabal, v. 26, n. 1, p. 53-56, abr. 2004.

REIS, A. et al. Demografia de Euterpe edulis Martius (Arecaceae) em uma floresta ombrófila densa montana, em Blumenau (SC). Sellowia, Itajaí, v. 45/48, p. 13-45, 1996.

SCHULZ, M. et al. Juçara fruit (Euterpe edulis Mart.): sustainable exploitation of a source of bioactive compounds. Food Research International, [s. l.], v. 89, p. 14-26, 2016. 